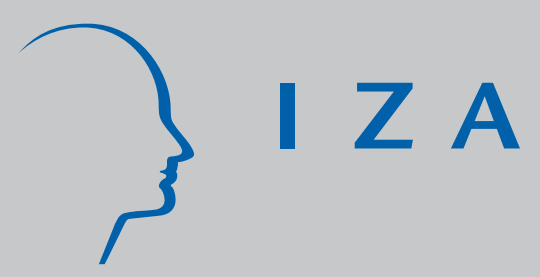

IZA DP No. 1274

Why Are Fertility and Women's Employment Rates So Low in Italy? Lessons from France and the U.K.

Daniela Del Boca

Silvia Pasqua

Chiara Pronzato

August 2004 


\title{
Why Are Fertility and Women's Employment Rates So Low in Italy? Lessons from France and the U.K.
}

\author{
Daniela Del Boca \\ University of Turin, CHILD \\ and IZA Bonn \\ Silvia Pasqua \\ University of Turin and CHILD \\ Chiara Pronzato \\ University of Turin and CHILD
}

Discussion Paper No. 1274
August 2004

IZA
P.O. Box 7240
53072 Bonn
Germany

Phone: +49-228-3894-0

Fax: +49-228-3894-180

Email: iza@iza.org

\begin{abstract}
Any opinions expressed here are those of the author(s) and not those of the institute. Research disseminated by IZA may include views on policy, but the institute itself takes no institutional policy positions.

The Institute for the Study of Labor (IZA) in Bonn is a local and virtual international research center and a place of communication between science, politics and business. IZA is an independent nonprofit company supported by Deutsche Post World Net. The center is associated with the University of Bonn and offers a stimulating research environment through its research networks, research support, and visitors and doctoral programs. IZA engages in (i) original and internationally competitive research in all fields of labor economics, (ii) development of policy concepts, and (iii) dissemination of research results and concepts to the interested public.
\end{abstract}

IZA Discussion Papers often represent preliminary work and are circulated to encourage discussion. Citation of such a paper should account for its provisional character. A revised version may be available directly from the author. 


\section{ABSTRACT \\ Why Are Fertility and Women's Employment Rates So Low in Italy? Lessons from France and the U.K.*}

According to the agenda for employment set by the EU in 2000 for the following ten years, the target for female employment was set at 60 per cent for the year 2010 . While Northern and most Continental countries have achieved this quantitative target, the Mediterranean countries are lagging behind. Labor market policies should be aimed to encourage women's participation and reduce the cost of working. However the persistence of a negative relationship between participation and fertility in these countries implies that it is important to take fertility into account. We analyze a model of labor supply and fertility, using data from the ECHP (European Community Household Panel) for the period 1994-2000, merged with regional data describing the available labor market opportunities in the households' environment.

JEL Classification: J2, C3, D1

Keywords: labor market decisions, fertility, childcare

Corresponding author:

Daniela Del Boca

Department of Economics

University of Turin

Via Po 53

10124 Turin

Italy

Email: daniela.delboca@unito.it

\footnotetext{
* This research is partially supported by the MURST, C.V. Starr Center of New York University and Compagnia di San Paolo. We have received helpful comments from Christopher Flinn, Linda Edwards, Maria Laura Di Tommaso and from participants in seminars held at Columbia University, CUNY Graduate Center, the Ramon Aceres Conference "Women and Wages" at the University of Alicante , the EPUNET Conference (2003), and the 2003 Annual Meeting of the ESPE (European Society for Population Economics). All errors and omissions are attributable to us.
} 


\section{Introduction}

In the Presidency Conclusions of the European Union Council in Lisbon, which took place in March 2000 and which set the agenda for employment in the Union for the following ten years, women's participation in the labor market had a central role. The overall target for female employment was set at 60 per cent for the year 2010. While Northern and most Continental countries have achieved the quantitative target, the Mediterranean countries are a lagging behind (Figure 1). However, women's education levels have been improving and social norms have been changing in favor of more women entering the labor force. Labor market policies should be aimed to encourage women's participation by reducing the costs of working. However the persistence of a negative relationship between participation and fertility in these countries implies that it is important to take into account that policies encouraging female employment may have a negative effect on fertility.

While the correlation between female participation and fertility has been negative and significant for several years across countries, it has became positive and weaker after mid 80s. However, if we consider only Southern European countries the correlation has not changed sign. Because of these different characteristics, the research focusing on the relationship between women's participation and fertility has developed mainly in Southern European countries, where reconciling work and fertility appears to be still a very difficult task. On the contrary, in Northern European countries, economic research has focused on the effects of children on women's wages and careers.

In this paper, using the European Community Household Panel (ECHP) data, we analyze the cases of three European countries Italy, France, and the U. K. in very different positions regarding the Lisbon target. In Section 2 we present important facts that are likely to have affected the relationship between participation and fertility. In Section 3 we review some of the empirical results emerged from research in different countries. In Section 4 we discuss the analytical framework that has been used to study labor supply and fertility. In Section 5 we present the econometric method that we use to analyze women's fertility and participation. In Section 6 we describe the dataset used, while in Section 7 we present our empirical results. Section 8 contains some concluding remarks. 


\section{The facts}

The most recent data indicate important differences in the relationship between employment rates of women and fertility in different countries. This suggests that different countries are in different stages of development, and women are constrained by specific social and economic factors. Southern European countries, traditionally characterized by low participation rates, have suffered a decline in fertility since the 80s while Northern European countries (with high participation) have been characterized by an increase in fertility (Figure 2).

The comparison of relevant social policies can help to interpret these differences. In Northern European countries and in some Continental countries (like France), governments have developed policies with the objective of simultaneously encouraging fertility and the participation of women in the labour force. These programs have supported dual earner families while shifting some of the economic burden of child rearing to the state. Public childcare availability, generous optional maternity leave as well as part-time opportunities have allowed women to choose either to remain in the labour market during their childbearing years and maintain a continuous and stable relationship with the labor market or to take care of their children by using long optional maternity leaves. In the Anglo-Saxon countries, governments have implemented programs only for the poor. In this context, where long optional parental leave is not available, mothers have to choose between part-time work combined with the use of private childcare or leaving the labor market.

In Southern European countries, on the contrary, governments have developed high quality public childcare but limited in supply while the development of private services has been constrained in several ways by competition with the public sector and by strict regulations ${ }^{1}$. Public childcare is also characterized by extreme rigidity in the number of weekly hours available. This makes the service compatible with part-time work but not with full-time activities. Given that part-time work is very limited in Southern Europe, married women are forced to choose between no work or full-time work, neither of which is necessarily their preferred option. Therefore, married women who choose to work tend to have full-time work commitments which is not compatible with having a large number of children.

In Southern Europe where both part-time work and childcare (under 3

\footnotetext{
${ }^{1}$ Only $6 \%$ of children under 3 years of age in Italy use formal child care in comparison with $29 \%$ in France and 64 \%in Denmark.
} 
years) are rare, and optional parental leave is short, women need to rely on family support in order to continue working when their children are young. In countries such as France, both part-time jobs and childcare are available and optional parental leave is long in duration, women can actually choose whether to continue working during their child bearing years or take time off from work to take care of their children (Kamerman and Kahn 2000). In the U.K. though, in absence of a long optional leave, the available choice consists of part-time work and private childcare.

Finally the labor markets in South of Europe unlike those in the Anglo Saxon countries, are still characterized by strict rules regarding the hiring and firing of workers and by low availability of flexible employment arrangements. These labor market regulations have been largely responsible for the high unemployment rates particularly among women and youth. Especially in Italy, the hiring system, the high entry wage and the very strict firing rules severely restrict employment opportunities for labor market entrants. Since entry-level positions are hard to find, many children live with their parents until they find their first "stable" employment. Thus the labor market indirectly imposes high fertility costs on families even when the mother does not work, and therefore it discourages fertility both directly and indirectly. Due to the high unemployment rates, women may have hard times taking breaks in their working life during childbearing years, finding it difficult to re-enter the labor market.

Family networks compensate for the lack of flexibility of the service system. For example, extended family members, normally grandparents, often provide childcare services which complement the limited services provided by publicly-funded day care facilities. Financial support as well as potential help in childcare has been shown to significantly increase the probability of the mothers working and especially has an important effect on the probability of mothers' working full-time (Del Boca, 2002). The role of the family extends far beyond the completion of schooling by the children. Because of the limited access to credit and housing markets to individuals without stable employment, the Italian family traditionally provides income support to its children during their usually lengthy search for a stable, "protected" job. The family often acts also as a provider of job opportunities. This is related to the larger proportion in Italy of self-employment and small family firms in all sectors which allows more flexibility in hours as well as compensation of income among family members and represents an important feature of the Southern European labor market.

The differences across countries partly explain the different labor market outcomes for women over the life cycle. The participation of women by age 
is quite different in the three countries. In the U.K. a higher proportion of women work, more than in the other two countries considered but have to leave the labor market during childbearing years given the lack of optional parental leave. Italian and French women work relatively less but show a greater labor market attachment. In France this possibility is supported by longer parental leave and greater availability of childcare for the children under three. In Italy this is mainly supported by the extended family. These empirical facts indicate important differences that we will explore in the analysis below.

\section{Previous Empirical Results}

Earlier studies have focused mainly on individual characteristics (schooling and income) to analyze fertility and participation decisions. The changes in women's education affect wage rates as well as wage profiles, with important effects on participation and fertility decisions and on the timing of the events. In particular, highly educated women work also during the period surrounding a birth event and therefore education induces fertility postponement. These results imply that policies aiming at increasing women's education would have a positive effect on participation but uncertain effects on fertility, given evidence of a U-shaped pattern of fertility with education. In fact, when only the mother's time and market goods are required for child rearing, an increase in working women's wages induces both income and substitution effects on fertility (and on labor supply) and the U-shaped pattern of fertility with education can be interpreted in terms of the prevalence of income over substitution effect and to the fact that highly educated women have access also to the expensive private childcare system)(Gustaffson et al 1996, Wetzels 2001).

Changes in the occupational structure, especially for part-time employment, have expanded employment opportunities for women. However, the development of part-time opportunities has not increased equally in all advanced countries. Empirical analyses of several countries show that being a mother (compared with being childless) decreases the probability of choosing full-time work and increases the probability of working part-time (Bardasi and Gornick 2000). Ariza, de la Rica and Ugidos (2003) have analyzed the relationship between part-time and fertility in different European countries and found that working part-time affects fertility in different ways depending on the characteristics of the labor market and the social service system. In Italy, part-time seems to represent an important option to reconcile child 
rearing and work in a situation where the supply of formal childcare is scarce (Del Boca 2002).

The importance of the availability of part-time work on the reconciliation between working and having children depends on other characteristics of the environment. The impact of the availability of childcare services, for example, depends on the characteristics of the system (hours) and the existence of part-time opportunities in Southern Europe. ${ }^{2}$

The effect on fertility has been studied by Ermisch (1989) whose findings have suggested that the increased availability of market childcare is one possible explanation for the change in fertility. According to his results, the changing effect of increases in women's wages on fertility from negative to positive would be facilitated by the availability of formal childcare. Apps and Rees (2001) analyzed the effect of childcare systems and show that countries that support families by providing alternatives to domestic childcare rather than through direct child payments are likely to have both a higher female labor supply and higher fertility.

The availability of childcare services by the extended family can have a similar role. Recent analyses of the Southern European labor markets show that the availability of parents' help with the children supports the mothers' employment during childbearing. With specific reference to Italy, Chiuri (2000), Del Boca (2002) and Marenzi and Pagani (2003) found that, after controlling for a wide range of variables, women who can count on their parents' support (both monetary and non-monetary support) are more likely to participate in the labour market. Del Boca (2002) also found that grandparents' help increases the probability of having children and that this effect appears to be more important that the impact of formal childcare availability. This suggests that grandparents are an important substitute for formal childcare services. This role is particularly crucial in contexts where the childcare system is characterized by the low availability, relative high costs and where the rigidity of opening hours reduces the opportunities

\footnotetext{
${ }^{2}$ Improvements in child care options as well as variations in their costs have been associated with significant increases in the labor supply of mothers in most countries (Connelly 1992, Kimmel 1998, Ribar 1992). Recent research shows that in Southern European countries, child care availability seems to be more important than its costs. Del Boca (2002) and Del Boca, Locatelli and Vuri (2003) have analyzed the effect of child care on the participation of married women in Italy, and the specific characteristics of the supply of public and private child care systems. The studies reach similar conclusions, that is household labor supply depends on child care rationing rather than its costs. The estimate of the relationship between child care costs and labor supply shows that a reduction in child care costs increases the probability of mothers working part-time but has no effect on the probability of working full-time.
} 
of combining household work with work in the market. Another important dimension of family support involves husbands helping with housework and childcare. Recently several studies have attempted to understand causes and consequences of changes in the division of work within households. Ichino and Sanz de Galdeano (2003), Del Boca, Locatelli and Vuri (2003) have shown that when husbands help with the children both the likelihood of women working and the likelihood of mothers spending more time with their children increases. Italian husbands contribute less to housework and childcare than their European counterparts.

Cross country studies have shown that paradoxally Southern European countries, which profess to support the traditional role of the family, do much less than others to support actual families (Esping-Andersen 1999). Often Catholicism indicates the absence of a range of family-friendly policies including the availability of childcare, the integration of work and school hours, the encouragement of part-time work, all policies with important implications for cross-national variation both in female labor force participation and in fertility rates (Castles 2003). In these countries the relationship between participation and fertility became weaker and negative in contrast with the remaining European countries where the compatibility between work and fertility has increased over time, producing a positive relationship (Engelhardt, Kögel and Prskawetz 2003, Kogel 2004, Kolher, Billari and Ortega 2002).

\section{Methodological Framework}

For many years economists have neglected the analysis of fertility and its determinants, basically because of the difficulties of incorporating it rigorously into traditional theories of the consumer choice. Fertility was essentially considered a non-economic phenomenon, better understood by examining the religious beliefs or the biology of the couple. While there still is some debate in the profession regarding the appropriateness of examining nontraditional applications using the standard tools of neoclassical analysis, there has been a steady stream of empirical and theoretical studies of fertility decisions, both in static and dynamic frameworks. While empirical economists' ability to explain fertility decisions has been decidedly limited, there are encouraging signs of a resurgence of interest in this topic. Current empirical research tends to examine fertility decisions in a more realistic manner, in which the relationship between fertility and labor market participation decisions by 
women is explicitly addressed ${ }^{3}$. Moreover, it is clear that there is an extremely relevant distinction, originally drawn by Becker and Lewis (1973) and Willis (1973), between child quantity and quality decisions. Since the number of children is readily available in most household surveys, while child quality investment information is not, this dimension of the fertility decision has been largely neglected. Recently in a new work on child investment decisions (Brown and Flinn 2003), a more complete model of the quality and quantity process has been developed and taken to data.

With the increasing availability of household panel data, particularly for developed economies, much current work on fertility has focused on the impact of "environmental" variables on household fertility decisions. This is a natural development, since even in Western Europe, in which virtually all countries enjoy a high standard of living, we see very large differences in fertility and labor market participation patterns. While some of these differences may reflect cultural attitudes regarding gender roles, some may be produced by systematic differences in choices faced by citizens. It is this aspect of fertility choices that is emphasized in the empirical work we report below.

Our motivation for focusing on the institutional context is motivated by the following observations. Ignoring child quality investment issues, under the assumption that children are normal goods, the demand for children will increase with household income. Since husbands are not usually involved in childcare activities, an increase in the husband's wage has the same positive effect on the demand for children as an increase in the household's non-labor income. On the contrary, since child rearing is a time intensive activity for the mothers, increasing wives' wages could have a negative effect on the demand for children.

Based on large national surveys, it has recently been observed that the negative association between the presence of young children and the mother's attachment to the labor force that characterize the empirical relationship between fertility and female labor force participation in most countries has become much weaker and less significant. There are a number of possible explanations for the reduction in the association between fertility and work. These include the availability of market substitutes (childcare services) for the mother's time or non-market substitutes (husband's or other relative's help in childcare activities), or the presence of part-time jobs that allows women to remain attached to the labor market while rearing their children.

The possibility of purchasing childcare (an imperfect substitute) for the

\footnotetext{
${ }^{3}$ See Browning (1992) for an excellent review of the literature on fertility decisions.
} 
mother's time in child rearing weakens the link between a woman's wage and the cost of an additional child. Mothers with high wages may purchase a much larger proportion of childcare time. For them higher wages have little effect on the costs of children making it more likely that they increase fertility by raising family income. Similar situation can arise in countries where other relatives provide less expensive non-market substitutes for mother's time. There are various ways in which the extended family acts as a substitute for the lack of market opportunities. Family networks seems to compensate for the lack of flexibility of the service system. For example, extended family members, most often grandparents, very often provide childcare services which complement the limited services provided by publicly-funded day care facilities. Recent analyses have shown that coresiding increases the probability of participation, even if such probability decreases as the parent grows older (age can be interpreted as an indicator of health) (Del Boca 2002, Chiuri 2000).

While the early literature introduced the presence of children (number and age of children in the home) as exogenous regressors in labor market participation equations, more recent analyses have insisted that these variables are potentially endogenous and therefore the results from earlier studies should be viewed with caution. Some authors attempted to address the endogeneity of fertility in the participation decision by adopting an instrumental variable methodology, whereby auxiliary equations are estimated for number of children and predicted values are substituted for the presence of children (see Browning 1992). The main challenge in doing this has been how to identify instruments, i.e., variables that influence the fertility decisions without also affecting the participation decision directly. ${ }^{4}$

More recently, fertility and labor market participation decisions have been recognized as the joint result of the maximization of household expected lifetime utility under budget and time constraints using an explicit dynamic framework. The desired participation status and the desired number of children depend on the whole sequence of prices and wages (which themselves may be endogenous) and on household preferences. The two types of decisions are therefore simultaneous in the sense that they are the solution to a common constrained maximization problem (Cigno 1991, Rosenzweig and Wolpin 1980, Hotz and Miller 1988, Moffitt 1984, Francesconi 2002)

The increasing availability of panel data has also allowed researchers

\footnotetext{
${ }^{4}$ In searching for suitable instruments for fertility, researchers have looked for sources of unplanned births, like the presence of twins and to the availability and cost of contraceptives (Rosenzweig and Wolpin 1980).
} 
to consider the dynamics involved in the relationship between births and women's work status and has made it possible to take into account important omitted factors, such as fecundity, tastes, and other individual and marriagespecific traits, which are important factors in explaining the decision to have children and unobservable to the researcher.

The econometric specification of the fertility and labor supply decision rules are assumed to be quasi-reduced form representations of demand functions that represent the solutions to an intertemporal optimization problem.

We will outline the dynamic random utility model setup employed in the empirical work below. A latent variable structure is assumed for both decisions. To illustrate, consider the following two equation system. Let the net value of being employed at a point in time be given by

$$
P_{i, t}^{*}=H_{i, t} \beta_{1}+Y_{i, t} \beta_{2}+E_{i, t} \beta_{3}+u_{i, t},
$$

where $H_{i, t}$ is a $(K \times 1)$ row vector containing observed variables measuring the human capital of the woman in household $i$ at time $t$ (exclusive of prior labor market experience), $Y_{i, t}$ is the vector of incomes of the household at time $t$, that excludes the wife's earnings, and $E_{i, t}$ is the vector of variables describing the economic environment (the labor market). The term $u_{i, t}$ is a disturbance term, the distributional properties of which will be discussed below.

The latent variable representing the net returns to an additional child in period $t$ is given by

$$
F_{i, t}^{*}=H_{i, t} \delta_{1}+Y_{i, t} \delta_{2}+E_{i, t} \delta_{3}+v_{i, t},
$$

The term $v_{i, t}$ is a disturbance term and is not assumed to be distributed independently of $u_{i, t}$.

Define the variable $d_{i, t}^{p}=1$ if the woman in household $i$ participates in the market at time $t$, and set $d_{i, t}^{p}=0$ if not. Define the birth outcome in a similar way, that is, let $d_{i, t}^{f}=1$ if there is a birth to household $i$ during period $t$ and set it equal to zero if this is not the case. Then we have that

$$
d_{i, t}^{p}=1 \Leftrightarrow P_{i, t}^{*}>0
$$

and

$$
d_{i, t}^{f}=1 \Leftrightarrow F_{i, t}^{*}>0 .
$$

Now we turn to the specification of the distribution of the disturbances. We assume that the two disturbances can be written as follows:

$$
\begin{aligned}
& u_{i, t}=\eta_{i}^{p}+\varepsilon_{i, t}^{(1)} \\
& v_{i, t}=\eta_{i}^{f}+\varepsilon_{i, t}^{(2)},
\end{aligned}
$$


where $\varepsilon_{i, t}^{(j)}$ is independently and identically distributed as a logistic random variable, $j=1,2$. We assume that the permanent component of each disturbance term is potentially not independently distributed with respect to the observable characteristics included on the right hand side of its respective equation. Furthermore, the characteristics of $\eta_{i}^{p}$, and $\eta_{i}^{f}$ are not assumed to be independently determined. We shall say more regarding our distributional assumptions below in the econometric section.

By specifying the entire sequence of exogenous characteristics and the unobservable individual specific characteristics $\left(\eta_{i}^{f}, \eta_{i}^{p}\right)$, our model will generate a distribution over possible sample paths of fertility and labor market participation outcomes. Comparative statistic exercises can be performed by changing elements of $\left\{H_{i, t}, E_{i, t}, Y_{i, t}\right\}_{t=1}^{S}$ or $\left(\eta_{i}^{p}, \eta_{i}^{f}\right)$ and examining the resulting change in the distributions of these events.

Our main interest in this paper is on the impact of variables affecting the cost of children on the decision to have a child and to work. We will examine the impacts of the variables at our disposal by estimating the parameters of the decision model discussed above. Before turning to the empirical results, we must first deal with econometric issues that center around the treatment of the time invariant unobservables.

\section{Econometric Methods}

In our analysis of fertility and female labor supply, we want to take into account some of the relevant characteristics of the institutional environment, indicators of levels of family support available to the household, and standard demographic characteristics, as well as other factors assumed unobservable to the analyst. One of the limitations of the economic analysis of fertility is in fact the omission of factors such as fecundity, tastes, and other individual and marriage-specific traits which are important factors in explaining the decision to have children. Many, or most, of these individualspecific factors affecting the decision to have a child are unobservable to the researcher. To deal with this issue we model the two decisions with a logit specification. This comes from a latent variable model in which the disturbance term is logistically distributed. When analyzing one binary choice variable, let individual $i$ experience the event in period $t$ with probability given by

$$
p\left(d_{i t}=1 \mid X_{i t}, \eta_{i}\right)=\frac{\exp \left(X_{i t} \beta+\eta_{i}\right)}{1+\exp \left(X_{i t} \beta+\eta_{i}\right)}, i=1, \ldots, N ; t=1, \ldots, T
$$


where $X_{i t}$ is a vector of covariates associated with individual $i$ in period $t, \beta$ is an (unknown) associated parameter vector, $\eta_{i}$ is an individual-specific, timeinvariant error term which is unobservable to the analyst, $T$ is the number of observations available for each household, and there are $N$ households in the sample.

In our application, we actually are modeling two decisions simultaneously, the participation decision and the fertility decision. Let $d_{i t}^{j}$ be an indicator variable which takes the value 1 for individual $i$ where $j=f$ for a birth and $j=p$ for labor market participation. We specify the probability that $d_{i t}^{f}=1$ and $d_{i t}^{p}=1$ as

$$
\begin{aligned}
p\left(d_{i t}^{f}\right. & \left.=1, d_{i t}^{p}=1 \mid X_{i t}^{f}, X_{i t}^{p}, \eta_{i}^{f}, \eta_{i}^{p}\right)=p\left(d_{i t}^{f}=1 \mid X_{i t}^{f}, \eta_{i}^{f}\right) p\left(d_{i t}^{p}=1 \mid X_{i t}^{p}, \eta_{i}^{p}\right) \\
& =\frac{\exp \left(X_{i t}^{f} \delta+\eta_{i}^{f}\right)}{1+\exp \left(X_{i t}^{f} \delta+\eta_{i}^{f}\right)} \times \frac{\exp \left(X_{i t}^{p} \beta+\eta_{i}^{p}\right)}{1+\exp \left(X_{i t}^{p} \beta+\eta_{i}^{p}\right)}
\end{aligned}
$$

where $X_{i t}^{j}$ are the exogenous variables in the index function for decision $j, \beta_{j}$ is the coefficient vector associated with the exogenous variables $X_{i t}^{j}$, and $\eta_{i}^{j}$ is the individual specific constant term in the index function for decision $j$.Within this framework two estimators are appropriate under various assumption regarding the individual effects which may or may not be correlated with the explanatory variables.

The first estimator we consider is based on the assumption that the two disturbances can be written as follows:

$$
\begin{aligned}
& \eta_{1}^{p}=\eta_{2}^{p}=\eta_{3}^{p}=\ldots=\eta_{N}^{p} \\
& \eta_{1}^{f}=\eta_{2}^{f}=\eta_{3}^{f}=\ldots=\eta_{N}^{f}
\end{aligned}
$$

We assume that the permanent component of each disturbance term is independently distributed of the observable characteristics $\left(X_{i t}^{f}, X_{i t}^{p}\right)$ included on the right hand side of its respective equation. Furthermore, the characteristics of $\eta_{i}^{p}$ and $\eta_{i}^{f}$ are not assumed to be independently determined. Thus since $\eta_{i}$ are uncorrelated with $\mathrm{X}$, all parameters can be consistently estimated using maximum likelihood methods by simply pooling the crosssectional information.

However this assumption seems problematic, since a woman who enjoys working may invest more in schooling so as to increase her wages when employed. Or she may be willing to marry a poorer husband since she plans to supplement household income with her own earnings.

The second estimator is based on the assumption that individual parameters $\left(\eta_{i}^{f}, \eta_{i}^{p}\right)$ are allowed to be related in an unknown way to the sequence 
of the exogenous variables. In particular, we make no assumption regarding the functional form of the distribution of these variables on this sequence. Chamberlain (1980) defined a conditioning scheme that transforms the data in such a way that the terms $\left(\eta_{i}^{f}, \eta_{i}^{p}\right)$ are eliminate and the simultaneity problem is avoided. The outcome of this conditioning is that coefficients associated with time invariant characteristics cannot be identified. Other parameters will be identifiable, and will be robust with respect to any possible variation on the manner in which the unobservable heterogeneity is related to observable heterogeneity. Moreover, after transforming the data and eliminating the unobserved components from each equation, we can estimate the model parameters $\beta$ and $\delta$ in isolation - that is, we can estimate the two equation model by estimating each equation in isolation.

The estimator works off of timing variability. To illustrate it, consider the case in which we observe the first two decision periods, so that $T=2$, and consider the participation decision. The conditioning scheme is to look at the relative likelihood of participating in the first period given that the individual worked in exactly one of the two periods. The fixed effects logit estimator allows us to isolate the effects of a subset of the variables included in the analysis on the probabilities of work and having children allowing for unobserved individual-specific effects which have an unrestricted relationship with the included regressors. We use the conditional logit estimator proposed by Chamberlain to analyse jointly the decisions of having children and working.

The cost of using this rather flexible estimation method is the inability to determine the effect of variables which do not vary over time (at the individual household level) on the probability of having a child or working in any given period. From the point of view of conducting policy analysis, which typically requires having access to estimates of all behavioral parameters, this is a serious problem. Moreover, one should be aware that the requirements for consistency of the fixed effects estimator in the discrete choice case are severe. Not only must the preference shock follow a logistic distribution, but the time invariant unobservable must not have a time varying impact on the likelihood of the event. For example, if the impact of the unobservable in the fertility index function is a function of time (age), then this shows up as $\psi_{t} \eta_{i}^{f}$ for individual $i$ at age $t$. Even if the $\psi_{s}$ are identical for all individuals in the population, the fixed effects logistic estimator will no longer be consistent. In other words, consistency requires the factor loadings $\psi_{1}, \psi_{2}, \ldots$ to be constant. As we can see from this brief discussion, the optimality properties of this estimator are extremely "delicate." 
The conditional maximum likelihood estimators are consistent no matter what the form of the dependence between an individual's characteristics and the value of her unobserved "type," and will also be consistent if the "error terms" are correlated across sample members in any manner. The form of the dependence between the scalar random variable $\eta_{i}$ and the covariates $X_{i}$ is not specified; in particular, the estimator for $\beta$ proposed by Chamberlain is consistent no matter what the form of the conditional distribution of $\eta_{i} \mid X_{i}$. The idea behind the estimator is to find distributions of the data which are functions only of $\beta$ and not the problematic $\eta_{1}, \ldots, \eta_{N}$. Define the total number of periods in which the individual experiences the event by $D_{i}=\Sigma_{t=1}^{T} d_{i t}$. This conditioning method to eliminate the fixed effects can be used for any set $D$ which is greater than 0 and less than $T$. Just as we do not restrict the form of dependence between $X_{i t}^{j}$ and $\eta_{i}^{j}$, we also do not make any assumption concerning the relationship between $\eta_{i}^{f}$ and $\eta_{i}^{p}$. Given the independence of the decisions $f$ and $p$ conditional on the $X s$ and the $\eta s$, and given that the fixed effects estimator defined below conditions on the $X s$ and eliminates the $\eta s$, the estimator for each decision $j$ is independent of the estimator for the decision $j^{\prime}$.

This simple functional form can be used to build likelihood functions which yield consistent maximum likelihood estimators of identified elements of $\beta$ for each $D$ between 1 and $T-1$. In our application of the fixed effects logit estimator, $T$ is at most equal to 7 . In this case, subsamples of individuals who experience the event fewer than seven times and more than once can be used to estimate $\beta$ consistently using this method. Chamberlain proved that the conditional likelihood estimator is consistent and asymptotically normally distributed under standard regularity conditions. In addition to implementing the conditional likelihood estimator on panel data, we also estimate cross-sectional logit specifications. When estimating the logit models, the entire available sample for each year is used. Besides being based on much larger samples, the cross-sectional logit estimator yields coefficient estimates for each variable in the appearing in the index function, even those with values which are time-invariant for each individual, but if and only if $\eta_{1}^{f}=\eta_{2}^{f}=\ldots=\eta_{N}^{f}$ and $\eta_{1}^{p}=\eta_{2}^{p}=\ldots=\eta_{N}^{p}$ which is a formal way of stating that households must not systematically differ in terms of any unmeasured variables. We test this restriction using standard Hausman tests: if the restriction is rejected, then we conclude that the cross-sectional logit estimates are inconsistent, although the fixed effects estimates will be consistent. However, as we stated above, the testing exercise concerns a very 
restricted model (logistic distribution) ${ }^{5}$.

\section{The Data}

Our empirical analysis utilizes seven year of panel data from the (ECHP), a standardized multi-purpose longitudinal survey coordinated and supported by Eurostat, which studies and compares the Member States of the European Union. The survey involves annual interviewing of a representative panel of households and individuals in each country, covering a wide range of topics on living conditions such as income, employment, poverty and social exclusion, housing, health, migration and other social indicators. The unit of analysis is the family and, within the household, all individuals older than sixteen. Nevertheless, it is possible to get information about all family members, including children under sixteen (see for a detailed description of ECHP data Locatelli, Moscato and Pasqua 2000).

We consider Italy, France and the U.K. For our analysis we select all households in which women are in the age range 21-45, married or cohabitant, so as to exclude those who might be still enrolled in school or retired. For the analysis of fertility, the age restriction serves to ensure that women included in the final sample will have a high probability of being fecund. The sample size after excluding women who did not meet the age criteria or who had missing information on the variables included in the analysis was 16,813 for Italy, 14,246 for France and 8,735 for the U.K. for participation equation, while in the fertility equation the sample is 14,716 for Italy, 12,572 for France and 7,432 for the U.K.

In order to use the conditional maximum likelihood estimator we need to limit our analysis to those women who change status over the observation period. For the participation analysis our sample include wives who worked at least one period and fewer than seven periods. For the fertility analysis

\footnotetext{
${ }^{5}$ The asympototic standard error estimates reported for the cross-sectional pooled logits are not "robust" standard errors. Estimates of robust standard errors, which allow for some degree of model misspecification, were computed and were very close to those reported (i.e., no greater or less than 10 percent for all coefficient estimates). In conducting the Hausman test, it is necessary that the estimator that is inconsistent under that alternative hypothesis (in this case, that fixed effects are present) be efficient under the null. Therefore to carry out the test we must assume that the assumed error structure is the correct one for the data, which implies that it would be inappropriate to use the robust covariance matrix in forming the test statistic. As a practical manner, we should note that the null hypothesis would be decisively rejected no matter which covariance matrix was employed.
} 
we include wives who had at least one birth and fewer than seven over the years of observation.

The dependent variables used in our analysis are whether the wife is working at the time of the interview and whether she has had a child in the year of the interview. The independent variables can be divided in four groups:

- Personal characteristics: Wife's age (and squared age); Education (three dummy variables: third level of education, second level of education and less than second level of education); Woman's non-labor income (in euros and divided by 1000) that includes husband's labor income and private non labor income of the household (excluding social transfers); Social transfers to the household (in euros and divided by 1000) ${ }^{6}$;

- Family structure: Presence of grandparents in the family;

- Labor market characteristics: Regional availability of part-time jobs, obtained as the ratio between part-time workers and total employed at regional level; Regional percentage of worker employed in self-employment;

- Year dummy: it is a dummy variable that takes value 1 for the years 1997-2001, value 0 otherwise.

The information concerning income is made comparable (using PPP) using specific coefficients provided by Eurostat in the ECHP dataset. The percentages of part-time jobs, for different European regions, are taken from REGIO, a Eurostat dataset providing regional data (Table A.1). Table 1 reports descriptive statistics for the variable used in the empirical estimation. The percentage of women working is higher in France and in the U.K. than in Italy. Women in France have the highest probability of having a child, while Italy shows the lowest percentage of women having children in the period considered. One of the most remarkable difference concerns education. In the U.K. has the highest share of women with higher education. However we have to take into account that a Bachelor's degree implies only three years in the U.K., while in Italy it implies at least four years. In France and the U.K. women have higher private income as well as social transfers with strong differences in the composition.

We can observe the average percentage of part-time workers in the area of residence of women in the sample (Table A.1). In the U.K. part-time works seems to be more widespread. In Italy the availability of part-time jobs is very limited, without significant increases in the period considered. Self-employment is the highest in Italy and the lowest in the U.K. Unfor-

\footnotetext{
${ }^{6}$ This variable includes unemployment, education, family, sickness, invalidity, housing, old age related benefits.
} 
tunately information about family policies such as parental leave or formal childcare are not available for the period considered and for all regions in the three countries considered and therefore cannot be included in our empirical analysis.

\section{Empirical Results}

As shown in Figure 1 the cross country correlation between participation and fertility has become positive in the last few years. The cross-region analysis for the countries we consider is, however, different. While for Italy there emerges a negative and marginally significant (-.478) correlation, for France the correlation is positive and significant (.744) and for the U.K. is close to zero (Figures 3a-3c). These differences are likely to have implications for the analysis of the effect of policy implementation.

We first estimate a model in which the data from all countries are pooled (Tables 2 and 3), and then we reestimate the model separately for each country (Tables 4-7). We can compare the cross-sectional and fixed effects estimators of common parameters when such a comparison is possible, i.e. when the coefficient is associated with a time-varying variable. The estimates of comparable parameters are in some cases substantially different between the cross-sectional logit and conditional likelihood estimators. In general, the cross-section estimates are larger in absolute value and estimated more precisely than the fixed effect ones (which is to be expected since they are effectively based on much larger samples). The fixed effect conditional logit is estimated only on women who changed states, that is, in our case, women who have been employed continuously and women who have never been employed in the seven years considered are excluded from the sample. Similar selection conditions hold for the fertility case.

We discuss the results for the specification in which all countries are considered together, and we start from the fixed effects model. The effects of personal characteristics confirm to other findings reported in the recent literature on fertility and women's labor market participation. Table 2 shows the results for the employment equation. The wife's age has a negative (but not significant) effect on participation, with absolute value of the impact increasing in age. Women's non-labor income has the expected negative sign, as well as social transfers to the household. We then look at the effect of potential family support such as the presence of a grandparent in the household. We believe that this variable can be interpreted as potential help for childcare. The coefficient is positive but only marginally significant in 
the fixed effects model. The FE estimators of part-time and self-employment are positive.

The coefficients of the pooled cross-section estimator also include the effects of education and country dummy variables. While the FE estimator measures only the effect of within-household variation over the period, the cross-section estimator measures both the effect of the regional variability on the dependent variables at a point in time and time variation. The signs of the coefficients of those variables which are in both models are not dissimilar, but the coefficients are larger in magnitude and more precisely estimated in the cross-sectional estimator. Several differences are observed, however.

In the pooled cross-section the coefficient of the variables "self-employment" is not significant, while the coefficients of part-time and grandparents' presence are. The age effect is positive (but concave) and education has the expected positive and significant impact on participation. Finally living in Italy and France reduces the probability of being employed (relative to the U.K.), even conditioning on all the variables we have included.

In Table 3 we report the fixed effect estimates and the cross-section estimates for fertility. Age has a positive and concave impact. Women's nonlabor income and social transfers coefficients are negative and only the last one is significant for the fixed effects model. The presence of grandparents is positive and significant. The variable related to part-time opportunities is instead negative (but not statistically significant), as is the variable related to self-employment, that is instead significant. In the cross-section education has a positive effect on fertility as it was reported in Del Boca (2002).

The Hausman tests, comparing the fixed effects specification with the pooled cross-section specification, suggest a preference for the fixed effects estimator, both in the participation and in the fertility equations.

We now compare the estimates separately for each country (Tables 4-7). The results show that the effect of age on participation varies remarkedly across countries. It iseems to be consistently negative in the U.K., that is getting older reduces the probability of being employed, while it is positive for Italy and France. On the contrary, age has a positive effect on the probability of having a child (due to our age selection). Education has a positive effect both on the probability of working and on the probability of having a child. Only in the U.K. women with sendary education are less likely to have a child than women with primary education (excluded category). Women's non-labor income and social transfers have the expected negative effect on the probability of working in all countries (Colombino and Del Boca 1990, Colombino and Di Tommaso 1996, Di Tommaso 1999) as well as on the probability of having children, when significant. The negative impact on 
fertility may reflect a timing effect. Particularly in France and the U.K. where family benefits are a greater component of public transfers (Table A. 2 ), this result can reflect the effect of past fertility decisions, which implies a negative impact on the subsequent number of children. In France, for example, family benefits are paid only after the second child. Other studies have suggested the existence of a timing effect; higher family benefits would encourage early entry into motherhood but not a large family size (Cigno 1991, Gauthier and Hatzius 1997). Also the proportion of unemployment benefits are higher in France and the U.K.. Past labor market activities (or job search) may have a negative impact on the number of children. In Italy the composition of social transfers shows that instead $80 \%$ of social transfers are actually pensions (Table A.2), which explains the non significant effect.

What is the effect of labor market characteristics? Part-time opportunities have a positive impact on participation only in Italy. The different results across countries reflect differences in the characteristics of part-time employment (Table A.3). Part-time jobs in Italy are characterized by similar job protection and social benefits as full time jobs and consists mainly of permanent positions and middle-level jobs. In France and the U.K. part-time employment consists mostly of temporary positions and is more widespread but only among the least educated. In terms of the age distribution of parttime job holders, in France it is more widespread among the very young while in the U.K. it is more concentrated among women ages 25-35, and among older women. Table A.3 shows self-reported data which indicate a much higher proportion of part-time workers in France would like to work full time and consider part-time an involuntary choice. In spite of the characterization of part-time opportunities as better "jobs" in Italy, we still find a negative effect on fertility when analyzing the FE estimator, given the negative cross-regional correlation between participation and fertility (see Figure 3a), but the positive correlation between women's participation and part-time jobs opportunities.

Self-employment is positively related to participation in Italy and in France. In Italy, in particular, self-employment seems to represent a way to find employment opportunities with more flexible hours in a labor market characterized by very tight labor regulations and high unemployment rates. Due to high unemployment rates women may have a difficult time taking breaks in their working life during childbearing years, and they find it difficult to re-enter the labor market when this period is over. Nevertheless, the impact on fertility is negative in all countries indicating the impact of a greater income volatility in the self-employment state. The different characteristics of self-employment in the three countries are shown in Table 
A.4. Compared with France and the U.K., self-employment in Italy is more widely represented in the service sector and among higher educated workers. The presence of grandparents (when significant) has a positive effect on participation since they represent an important source of childcare services for employed mothers (Del Boca, Locatelli and Pasqua 2000).

\section{Interpretations and Conclusions}

The empirical results we obtained show that the econometric analysis of participation is more meaningful than is the analysis of fertility. This shows that the presence of unobservables is more crucial here. The results show that when controlling for all personal, family and available environmental characterics, Italian women still work significantly less than women in France and the U.K..

The differences in education seem to be an important factor with important effect on participation without negative implication on fertility: if Italian women had the education distribution of the women in the U.K., their participation rate would increase from 46.8 to 50.1 and the birth rate would increase from 4.1 to 4.3 .

The differences in part-time opportunities are also important for participation but may have negative implications on fertility. If Italian women, in fact, had access to the same number of part-time positions as women in the U.K., their participation would increase to 52.5 but the birth rate would decrease from 4.1 to 3.8. This result may be the outcome of two different effects. In a country where part-time is such a rationed opportunity, married women are forced to choose between no work or full-time work. The growth of the availability of a third option would change the choice set available but with ambigous results on fertility. If non working women chose to work part-time, their fertility rates may actually decline, while if full-time working women would choose to reduce their working schedule, their fertility may increase. The net effect on fertility depends on the sizes of these different flows.

When we analyze each country separately we see that personal characteristics have more similar effects in all countries (age, education non-labor income) than the "environmental variables". Part-time has a positive impact only in Italy, which is consistent with the more appealing characteristics of the part-time opportunities. In France and the U.K., part-time jobs seem to represent more of a temporary solution while searching for better job opportunities when young or to face difficult conciliation between market work 
and household activities during childbearing years. Self-employment has a positive effect in Italy and France probably because it helps in providing flexibility to leave and re-enter the labor market. The role of grandparents appears to be relevant since it represents an important substitute for formal childcare, affecting positively both participation and fertility.

The Lisbon target of $60 \%$ of female participation in 2010, almost achieved for France and already surpassed by the U.K., would require an increase of almost 20 percentage points for Italy, implying not only a constant increase in the level of female education, but important changes in the labor market. A recent European Union directive concerns the creation of more part-time jobs, as part of the overall Employment Strategy. The Mediterranean countries have created fewer part-time jobs, mostly because their labour markets are too rigid to enable firms to create them. If they liberalise their markets to make it easier for firms to create such jobs their aggregate employment rates will be likely to rise. Our results show that this policy may have a sizeable impact on participation but at the cost of lower birth rates.

This implies that married women need the extra provision for family care. The EU summit passed a recommendation that by 2010 member states should provide childcare to at least $33 \%$ of children under age three and at least $90 \%$ of children between age three and mandatory school age. However the characteristics of public childcare do not appear to be coherent with the time schedule of full time employment. This implies that a growth of both employment and fertility needs the combination of part-time and flexible childcare. The same objectives can be achieved if private initiatives are encouraged to set up small family-care units. These units would be run by a small number of individuals, most likely women with children, which is likely to increase women's employment opportunities. In fact private initiatives appear to be the driving force behind family care in the U.K. and the U.S, countries with high fertility and high-employment rates. 
Table 1

Descriptive Statistics

\section{European Commission Household Panel}

$\begin{array}{llll}\text { Variables } & \mathbf{1 9 9 4 - 2 0 0 0} & & \\ & \text { Italy } & \text { France } & \text { U.K. } \\ \text { Fertility } & .068 & .083 & .075 \\ & (.251) & (.275) & (.263) \\ \text { Participation } & .505 & .646 & .672 \\ & (.500) & (.478) & (.470) \\ \text { Woman's non-labor income (euro) } & 15,521 & 18,180 & 18,627 \\ & (10,909) & (17,987) & (14,329) \\ \text { Social transfers to the household (euro) } & 1,252 & 3,323 & 2,424 \\ & (3,587) & (4,336) & (3,831) \\ \text { Age of the wife } & 35.7 & 34.9 & 34.3 \\ & (5.748) & (6.331) & (6.382) \\ \text { Schooling level 1 (university) } & .077 & .298 & .352 \\ & (.266) & (.457) & (.478) \\ \text { Schooling level 2 (secondary) } & .414 & .422 & .157 \\ & (.493) & (.494) & (.364) \\ \text { Presence of grandparents } & .074 & .010 & .016 \\ & (.262) & (.100) & (.126) \\ \text { Part-time by region } & .070 & .163 & .252 \\ & (.014) & (.024) & (.017) \\ \text { Workers in self-employment } & .243 & .098 & .127 \\ & (.033) & (.032) & (.027)\end{array}$


Table 2

Participation Equation Estimates (Asymptotic Standard Errors in Parentheses)

\begin{tabular}{|c|c|c|}
\hline Variables & Fixed & Pooled CS \\
\hline \multirow[t]{2}{*}{ Age } & -.076 & $.145^{* *}$ \\
\hline & $(.070)$ & $(.018)$ \\
\hline \multirow[t]{2}{*}{ Age square } & $.003^{* *}$ & $-.002^{* *}$ \\
\hline & $(.001)$ & $(.000)$ \\
\hline \multirow[t]{2}{*}{ Tertiary Education } & - & $1.253^{* *}$ \\
\hline & & $(.032)$ \\
\hline \multirow[t]{2}{*}{ Secondary Education } & - & $.864^{* *}$ \\
\hline & & $(.025)$ \\
\hline \multirow[t]{2}{*}{ Non-labor income } & $-.008 * *$ & $-.010^{* *}$ \\
\hline & $(.003)$ & $(.001)$ \\
\hline \multirow[t]{2}{*}{ Social transfers } & $-.065^{* *}$ & $-.120 * *$ \\
\hline & $(.008)$ & $(.003)$ \\
\hline \multirow[t]{2}{*}{ Grandparents } & .350 & $1.030^{* *}$ \\
\hline & $(.254)$ & $(.065)$ \\
\hline \multirow[t]{2}{*}{ Part-time } & .015 & $.013^{*}$ \\
\hline & $(.034)$ & $(.007)$ \\
\hline \multirow[t]{2}{*}{ Self-employment } & .008 & .005 \\
\hline & $(.019)$ & $(.004)$ \\
\hline \multirow[t]{2}{*}{ 1997-2000 } & $-.394^{* *}$ & -.020 \\
\hline & $(.080)$ & $(.024)$ \\
\hline \multirow[t]{2}{*}{ Italy } & - & $-.893^{* *}$ \\
\hline & & $(.160)$ \\
\hline \multirow[t]{2}{*}{ France } & - & $-.179^{* *}$ \\
\hline & & $(.066)$ \\
\hline \multirow[t]{2}{*}{ Cons } & - & $-2.643^{* *}$ \\
\hline & & $(.345)$ \\
\hline N. observation & 11,859 & 39,794 \\
\hline log likelihood & $-4,565.7$ & $-24,534.3$ \\
\hline Hausman test (vs. pooled) & $140.7^{* *}$ & \\
\hline
\end{tabular}


Table 3

Fertility Equation Estimates

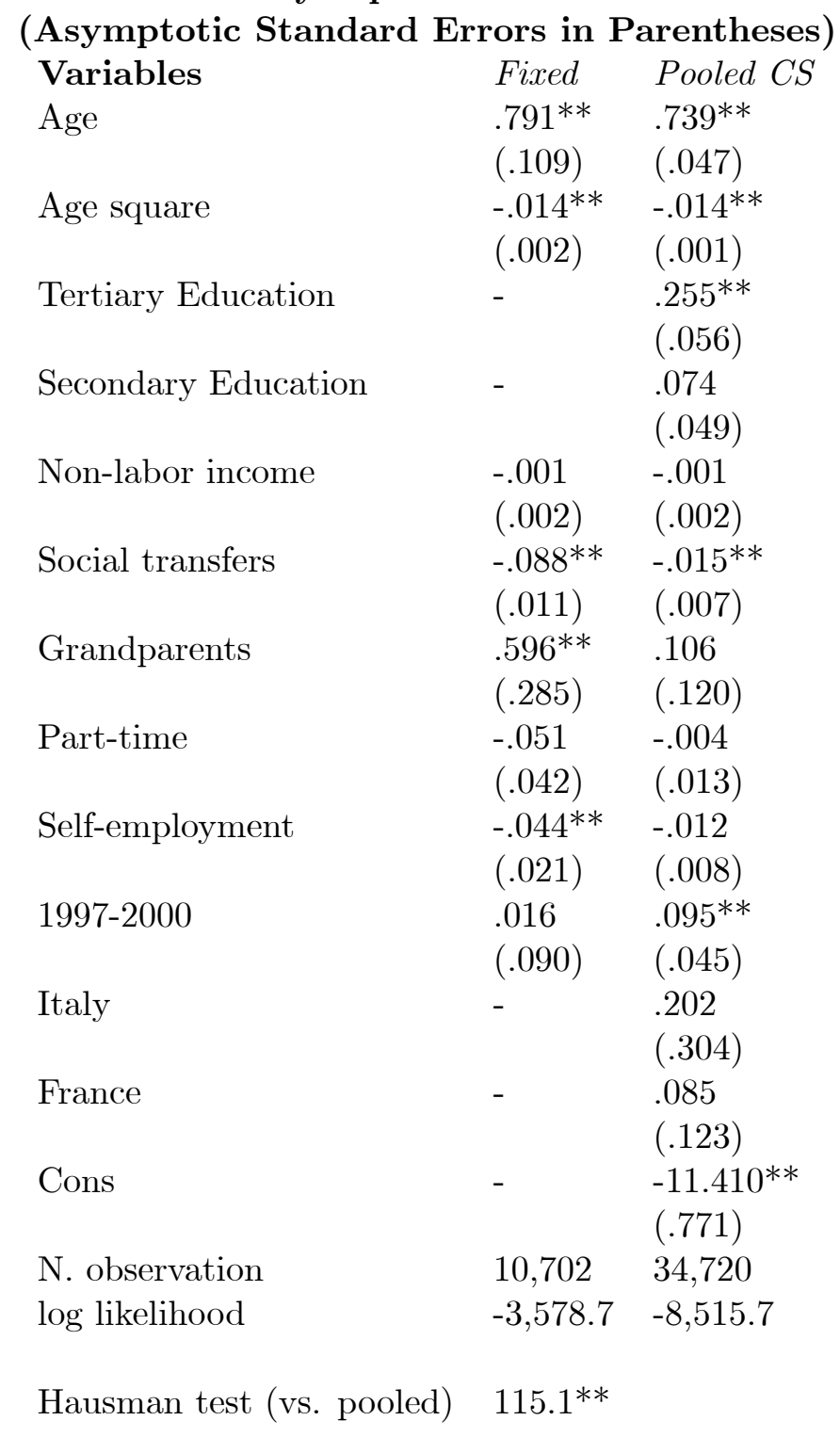


Table 4

Participation Equation Estimates

Fixed Effects

(Asymptotic Standard Errors in Parentheses)

$\begin{array}{llll} & \text { Italy } & \text { France } & \text { U.K. } \\ \text { Age } & .060 & .215^{* *} & -.721^{* *} \\ & (.141) & (.102) & (.151) \\ \text { Age square } & -.000 & -.000 & .011^{* *} \\ & (.002) & (.001) & (.002) \\ \text { Non-labor income } & -.021^{* *} & -.002 & -.016^{* *} \\ & (.006) & (.003) & (.006) \\ \text { Social transfers } & .001 & -.087^{* *} & -.121^{* *} \\ & (.013) & (.011) & (.023) \\ \text { Grandparents } & .189 & 1.343^{*} & -.543 \\ & (.328) & (.756) & (.534) \\ \text { Part-time (regional) } & .071 & -.025 & -.025 \\ & (.066) & (.062) & (.062) \\ \text { Self-employment (regional) } & .023 & .007 & -.016 \\ & (.027) & (.043) & (.038) \\ \text { 1997-2000 } & -.175 & -.764^{* *} & .000 \\ & (.140) & (.130) & (.159) \\ \text { N observation } & 3,856 & 5,153 & 2,850 \\ \text { log likelihood } & -1,484.5 & -1,956.6 & -1.076 .2 \\ & & & \\ \text { Hausman test (vs. pooled) } & 35.4^{* *} & 126.3^{* *} & 58.8^{* *}\end{array}$


Table 5

Fertility Equation Estimates

Fixed Effect

(Asymptotic Standard Errors in Parentheses)

Age

Italy France U.K.

Age square

$.203 \quad 1.170^{* *} \quad 1.027^{* *}$

$(.180) \quad(.173) \quad(.237)$

$\begin{array}{lll}-.005 & -.019^{* *}-.019^{* *}\end{array}$

Non-labor income

$\begin{array}{lll}(.003) \quad(.003) \quad(.004) & 0\end{array}$

$\begin{array}{lll}-.007 & -.002 & .012\end{array}$

$\begin{array}{lll}(.006) \quad(.003) \quad(.008) & 0\end{array}$

Social transfers $\quad-.009 \quad-.143^{* *} \quad-.087^{* *}$

$(.016) \quad(.016) \quad(.030)$

$\begin{array}{llll}\text { Grandparents } & .412 & .244 & -1.141\end{array}$

$\begin{array}{lll}(.339) \quad(.843) \quad(.758) & 0\end{array}$

Part-time $\quad-.210^{* *} \quad-.052 \quad .003$

$\begin{array}{llll} & (.174) & (.081) & (.076) \\ \text { Self-employment } & -.046^{*} & -.110^{* *} & -.033\end{array}$

$\begin{array}{lll}(.027) \quad(.052) \quad(.043) & (05)\end{array}$

$1997-2000$

$\begin{array}{lll}.010 & -.057 \quad .000\end{array}$

N observation

$\begin{array}{lll}(.149) \quad(.146) \quad(.188) & 0\end{array}$

log likelihood

$4,277 \quad 4,225 \quad 2,200$

$-1,410.6 \quad-1,389.9 \quad-742.2$

Hausman test (vs. pooled) $\quad 69.3^{* *} \quad 98.5^{* *} \quad 24.3^{* *}$ 


\section{Table 6}

\section{Participation Equation Estimates}

Pooled Cross Section

(Asymptotic Standard Errors in Parentheses)

$\begin{array}{llll} & \text { Italy } & \text { France } & \text { U.K. } \\ \text { Age } & .185^{* *} & .234^{* *} & -.063 \\ \text { Age square } & (.031) & (.031) & (.040) \\ & -.002^{* *} & -.003^{* *} & .001^{* *} \\ \text { Tertiary education } & (.000) & (.000) & (.000) \\ & 1.973^{* *} & 1.101^{* *} & .718^{* *} \\ \text { Secondary education } & 1.071) & (.052) & (.057) \\ & (.035) & .646^{* *} & .342^{* *} \\ \text { Non-labor income } & -.016^{* *} & -.045) & (.071) \\ & (.002) & (.001) & -.015^{* *} \\ \text { Social transfers } & -.023^{* *} & -.157^{* *} & -.211^{* *} \\ & (.005) & (.005) & (.009) \\ \text { Grandparents } & .393^{* *} & 1.621^{* *} & .850^{* *} \\ \text { Part-time } & (.078) & (.220) & (.198) \\ & .259^{* *} & -.075^{* *} & -.068^{* *} \\ \text { Self-employment } & (.014) & (.012) & (.016) \\ & .010^{*} & .020^{* *} & -.010 \\ \text { 1997-2000 } & (.005) & (.008) & (.010) \\ & -.346^{* *} & .030 & .196^{* *} \\ \text { Cons } & (.039) & (.044) & (.054) \\ & -5.859^{* *} & -2.944^{* *} & 3.498^{* *} \\ \text { N observation } & (.552) & (.519) & (.764) \\ \text { log likelihood } & 16,813 & 14,246 & 8,735 \\ & -10,613.3 & -8,409.7 & -4,879.7 \\ & & & \end{array}$


Table 7

Fertility Equation Estimates

Pooled Cross Section

(Asymptotic Standard Errors in Parentheses)

$\begin{array}{llll} & \text { Italy } & \text { France } & \text { U.K. } \\ \text { Age } & .570^{* *} & .903^{* *} & .614^{* *} \\ & (.077) & (.078) & (.091) \\ \text { Age square } & -.012^{* *} & -.016^{* *} & -.012^{* *} \\ & (.001) & (.001) & (.001) \\ \text { Tertiary education } & .700^{* *} & .213^{* *} & .081 \\ & (.119) & (.092) & (.097) \\ \text { Secondary education } & .192^{* *} & .083 & -.240^{*} \\ & (.071) & (.089) & (.134) \\ \text { Non-labor income } & -.004 & .001 & .001 \\ & (.004) & (.002) & (.004) \\ \text { Social transfers } & -.019 & -.022^{* *} & -.008 \\ & (.013) & (.010) & (.013) \\ \text { Grandparents } & .214 & .061 & -.590 \\ \text { Part-time } & (.150) & (.411) & (.401) \\ & -.022 & -.014 & .015 \\ \text { Self-employment } & (.031) & (.022) & (.027) \\ & -.009 & -.006 & -.025 \\ \text { 1997-2000 } & (.011) & (.015) & (.016) \\ & .176^{* *} & .136^{*} & -.084 \\ \text { Cons } & (.073) & (.077) & (.092) \\ & -8.316^{* *} & -13.784^{* *} & -9.886^{* *} \\ \text { N observation } & (1.224) & (1.211) & (1.541) \\ \text { log likelihood } & 14,716 & 12,572 & 7,432 \\ & -3,355.9 & -3,204.6 & -1,927.6\end{array}$




\section{Table A.1}

Italy Work Fertility Part-time Self-employment

North West

$65.0 \quad 5.5$

$69.2 \quad 6.2$

6.8

21.9

Lombardia

$60.1 \quad 6.4$

7.6

22.9

North East

$78.5 \quad 6.6$

8.3

24.7

Emilia Romagna

62.2

7.7

7.5

30.4

Center

$39.9 \quad 6.1$

6.1

28.3

Lazio

43.7

5.1

20.4

Abruzzo

31.9

5.0

5.2

29.6

Campania

30.7

8.0

6.6

21.2

South

$28.8 \quad 8.4$

6.9

23.6

Sicilia

29.3

8.8

7.4

27.1

25.8

France

Ile de France

73.8

8.9

$65.5 \quad 7.1$

12.4

15.7

6.7

Bassin Parisien

52.5

5.6

17.1

7.9

North Pas de Calais

$62.1 \quad 8.2$

16.3

5.6

Est

65.1

7.3

18.8

7.7

South West

65.3

6.6

17.9

12.9

Centre Est

62.9

8.1

18.2

15.2

Mediterranee

$65.0 \quad 6.9$

18.2

11.3

12.9 
Table A.1 (cont)

$U K$

Work Fertility Part-time Self-employment

North

71.1

8.1

26.4

7.4

Yorkshire and Humbershire $\quad 67.8$

6.7

26.2

11.7

$60.4 \quad 8.4$

25.1

13.2

East Anglia

69.8

25.8

13.2

$66.2 \quad 7.9$

25.0

13.4

$64.0 \quad 7.0$

27.6

16.2

63.7

24.3

12.7

70.5

7.9

24.3

24.9

63.5

6.9

23.7

12.8

10.9

72.6

6.4

11.8

Tab A. 2

Composition of Social Transfers. 1994-2000

Variables Italy France U.K.

$\begin{array}{llll}\text { Unemployment } & 5.0 & 10.0 & 2.5\end{array}$

$\begin{array}{llll}\text { Pensions } & 79.2 & 45.2 & 43.3\end{array}$

Family benefits $\quad 5.0 \quad 27.0 \quad 29.5$

$\begin{array}{llll}\text { Sickness } & 7.6 & 6.5 & 9.2\end{array}$

$\begin{array}{llll}\text { Education } & 1.8 & 2.8 & 3.4\end{array}$

Housing and other $\quad 1.4 \quad 9.5 \quad 9.6$ 
Tab A. 3

Distribution of part-time by age and schooling 1994-2000

\begin{tabular}{llll}
\multicolumn{4}{c}{ Female \% over total employment } \\
Variables & Italy & France & U.K. \\
Age & 14.0 & 18.5 & 30.5 \\
$16-20$ & 11.7 & 31.2 & 28.7 \\
$21-25$ & 11.9 & 19.0 & 12.8 \\
$25-30$ & 13.0 & 15.4 & 19.9 \\
$31-35$ & 14.6 & 18.4 & 33.9 \\
$36-40$ & 15.3 & 17.8 & 37.8 \\
$41-45$ & 15.9 & 18.3 & 33.1 \\
$46-50$ & 15.1 & 19.2 & 32.8 \\
$>50$ & 16.3 & 19.9 & 38.7 \\
Less than secondary education & 24.3 & 5.4 & 16.5 \\
Secondary education & 8.8 & 7.3 & 15.9 \\
Tertiary education & 4.5 & 10.7 & 14.0 \\
Temporary & 14.0 & 36.9 & 39.9 \\
\% married & 16.1 & 20.8 & 38.5 \\
involuntary $(*)$ & 19.0 & 41.1 & 3.3
\end{tabular}

Source: ECHP 
Tab A. 4

Distribution of Self-Employment by Age and Schooling and Sector. 1994-2000

\begin{tabular}{|c|c|c|c|}
\hline \multicolumn{4}{|c|}{ Female \% over total employment } \\
\hline Variables & Italy & France & $U . K$. \\
\hline \multicolumn{4}{|l|}{ Age } \\
\hline $16-20$ & 2.0 & 0.5 & 1.1 \\
\hline $21-25$ & 6.5 & 1.1 & 3.7 \\
\hline $25-30$ & 13.0 & 3.1 & 7.5 \\
\hline $31-35$ & 18.2 & 6.8 & 9.2 \\
\hline $36-40$ & 19.2 & 9.2 & 10.7 \\
\hline $41-45$ & 19.6 & 8.2 & 11.2 \\
\hline $46-50$ & 19.2 & 8.8 & 13.0 \\
\hline \multicolumn{4}{|l|}{$>50$} \\
\hline Less than secondary education & 29.2 & 10.5 & 11.8 \\
\hline Secondary education & 19.1 & 10.5 & 12.1 \\
\hline Tertiary education & 23.6 & 8.4 & 12.9 \\
\hline Service & 25.7 & 7.4 & 11.8 \\
\hline Manufacturing & 23.4 & 6.8 & 15.5 \\
\hline Agriculture & 58.8 & 69.1 & 44.5 \\
\hline$\%$ Married & 14.7 & 6.5 & 9.7 \\
\hline
\end{tabular}


Figure 1

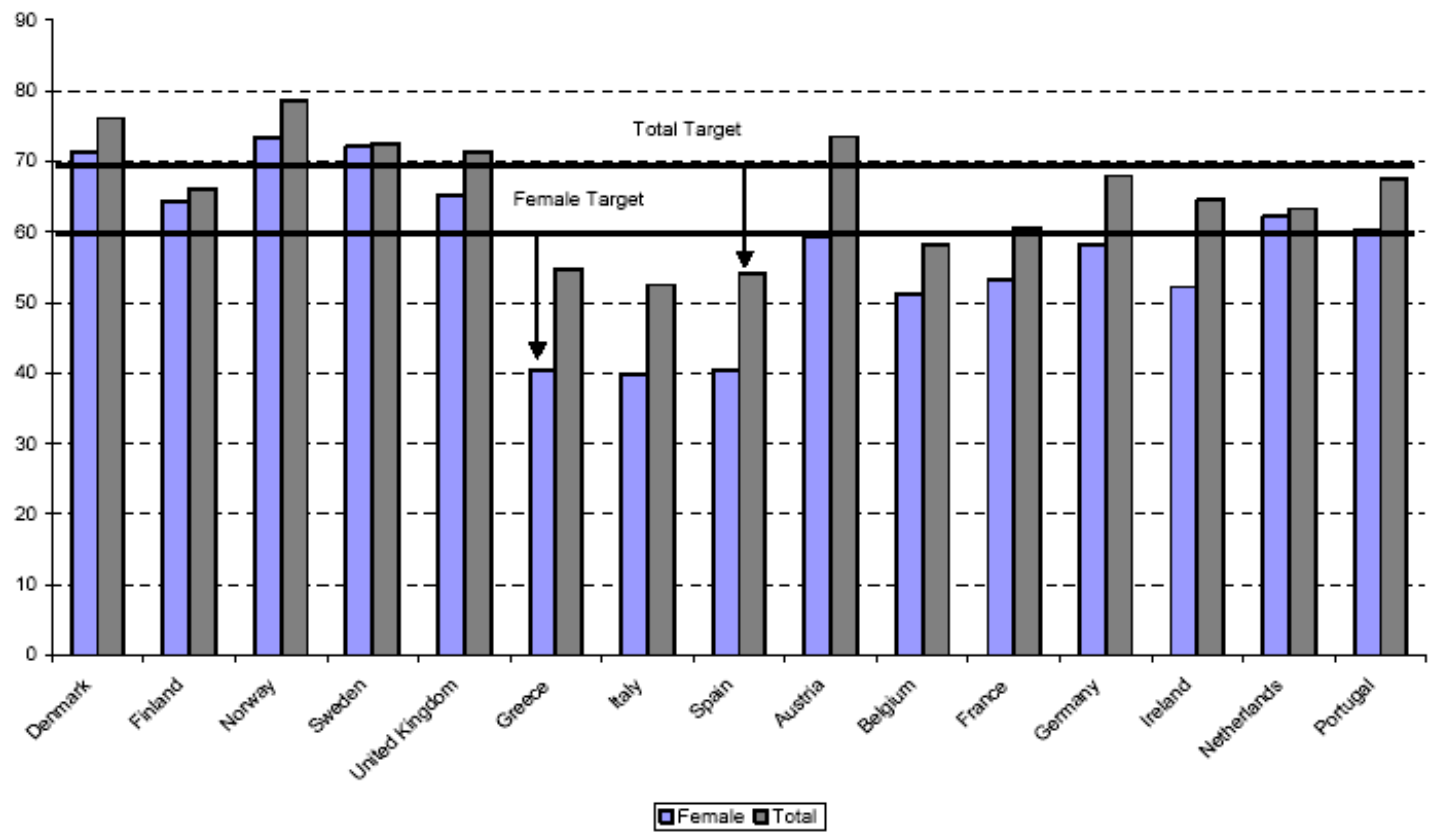

Source: Pissarides et al. (2003)

Figure 2

\section{Women's participation and fertility (2000)}

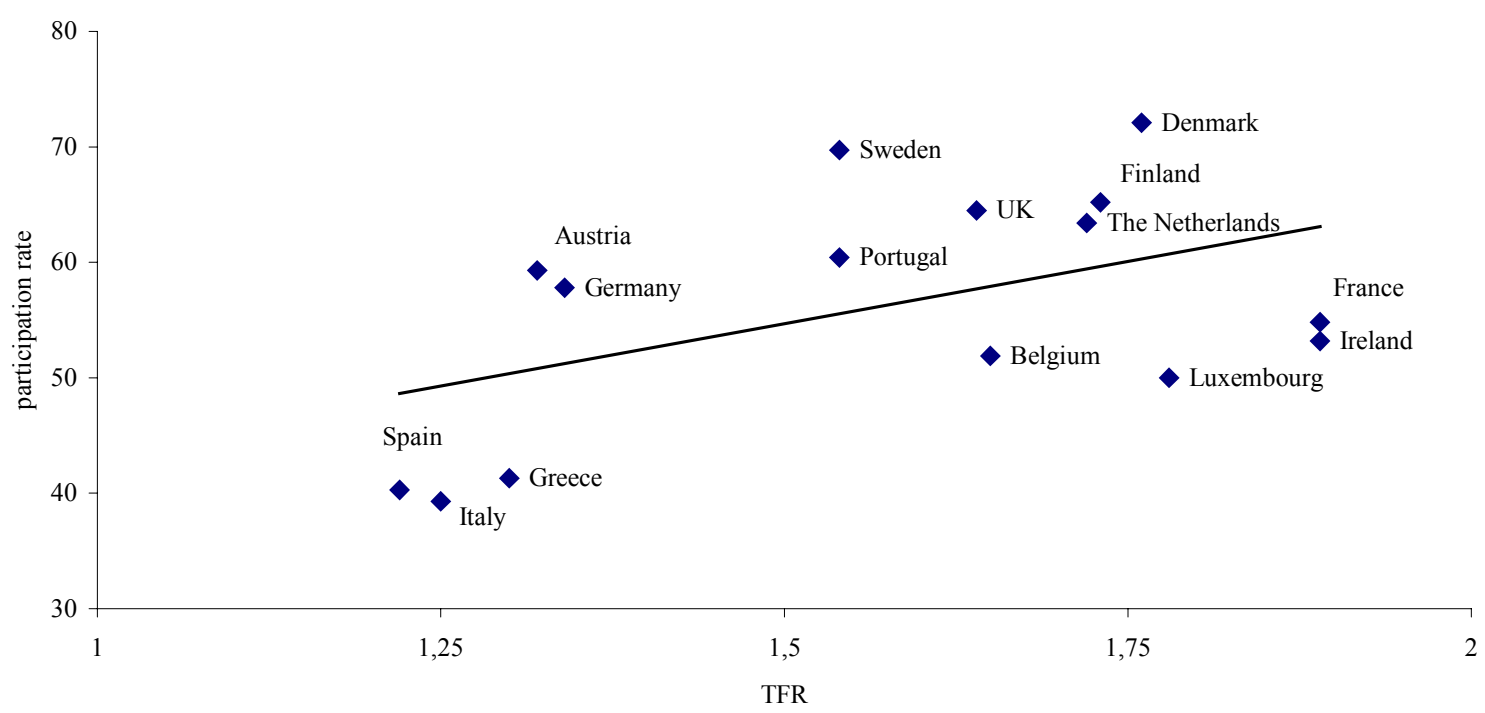

Source: our elaborations on $E C H P$ 


\section{Figure 3a}

\section{Correlation between women's employment and fertility}

\section{Italy (regions)}

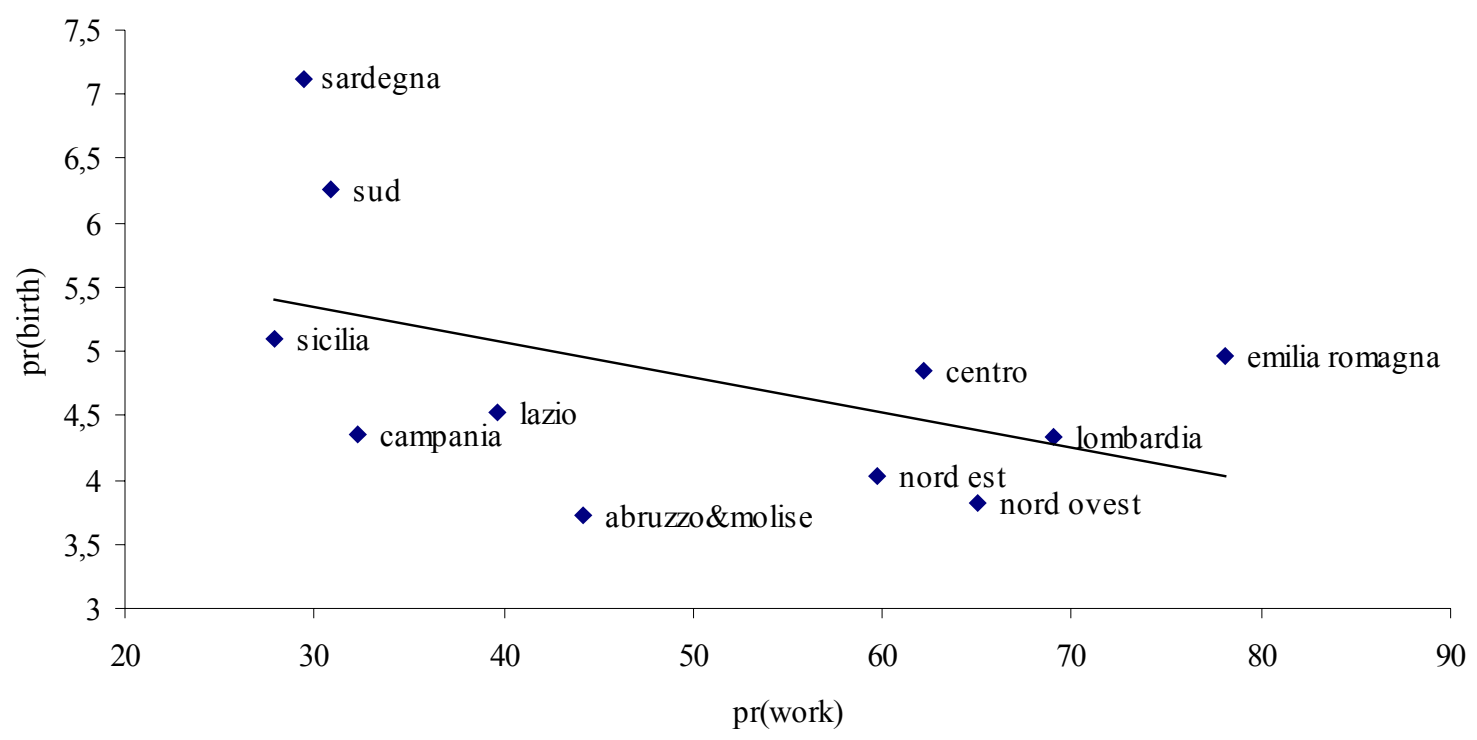

Source: our elaborations on $E C H P$

\section{Figure 3b}

\section{Correlation between women's employment and fertility}

\section{France (regions)}

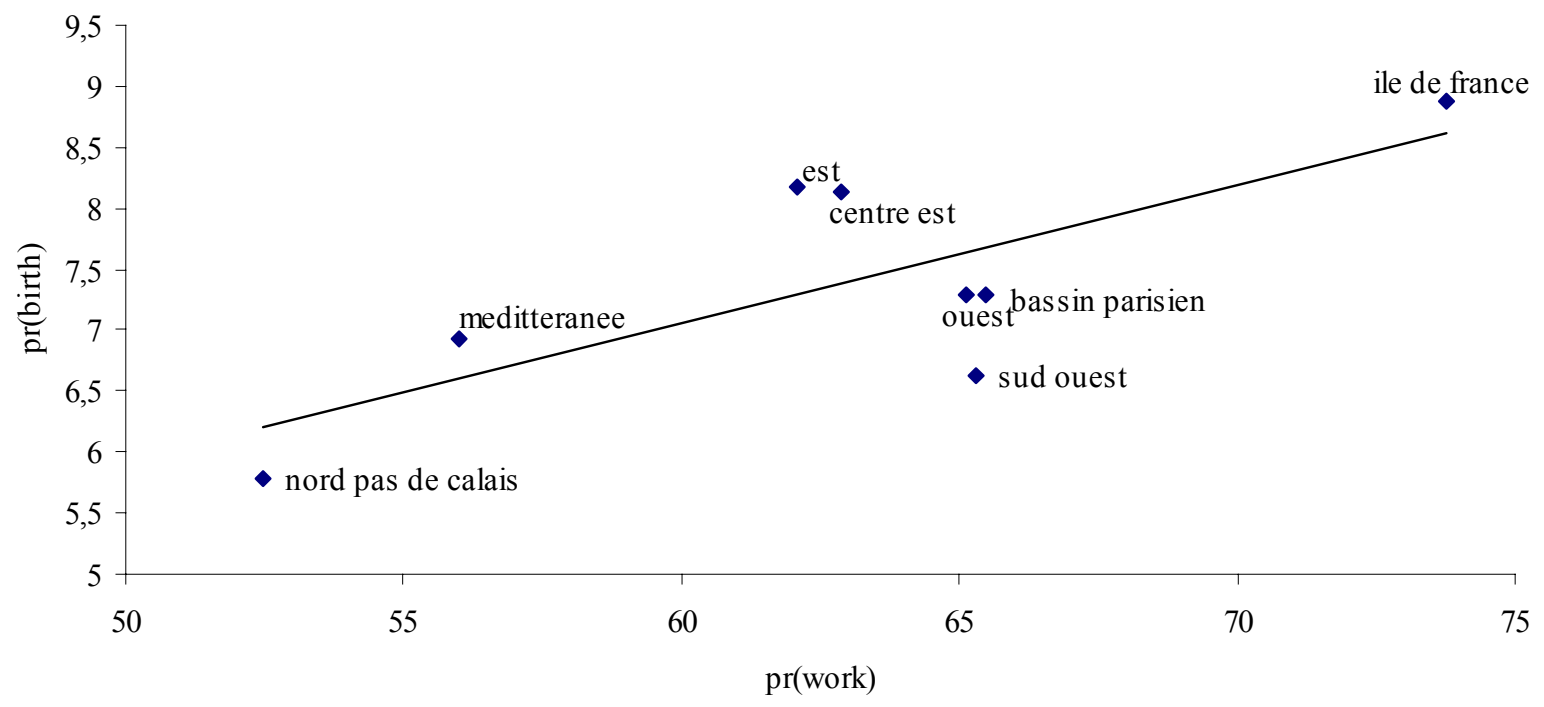

Source: our elaborations on $E C H P$ 


\section{Figure 3c}

\section{Correlation between women's employment and fertility}

\section{UK (regions)}

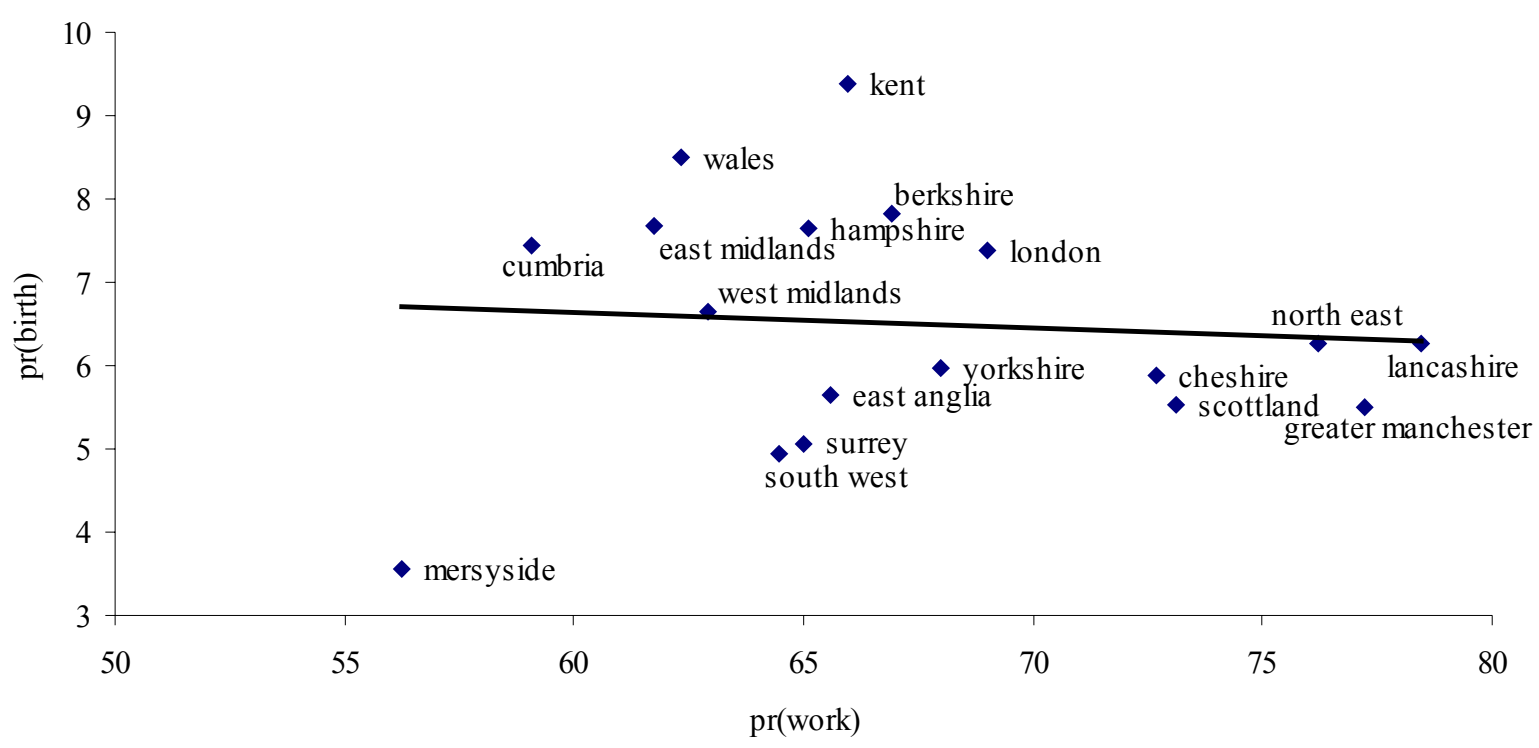

Source: our elaborations on $E C H P$ 


\section{References}

[1] Ariza A., De La Rica S. and Ugidos A., 2003, "The Effect of flexibility in working hours on fertility: A comparative analysis of selected European Countries", mimeo

[2] Ahn N. and Mira P., 2002, "A note of the relationship between fertility and female employment rates in developed countries" Journal of the Population Economics, 15, 667-682

[3] Apps A. and Rees R., 2001, "Fertility, Female Labor Supply and Public Policy", Discussion Paper No. 409, Institute of the Study of Labor (IZA), Bonn, Germany

[4] Bardasi E. and Gornick J. C., 2000, "Women and Part-Time Employment: Worker 'Choices' and Wage Penalties in Five Industrialised Countries", ISER Working Paper 2000-11

[5] Becker G. and Lewis, H.G., 1973, "On the Interaction between the Quantity and Quality of Children", Journal of Political Economy, 81, S279-S288

[6] Brown M. and Flinn C., 2003, "Child Investment and Child Quality", New York University mimeo

[7] Browning M., 1992, "Children and Household Economic Behavior", Journal of Economic Literature, 30, 1434-1475

[8] Castles F., 2003, "The World Turned Upside Down: Below Replacement Fertility, Changing Preferences and Family-Friendly Public Policy in 21 OECD Countries", Journal of European Social Policy, 13, 209-227

[9] Cigno A., 1991, Economics of the Family, Oxford University Press, Oxford

[10] Chamberlain G., 1980, "Analysis of covariance with qualitative data", Review of Economic Studies, 47, 225-238

[11] Chiuri M.C., 2000, "Quality of Child care and Household Labour Supply in Italy", Labour, 14, 97-118

[12] Colombino U. and Del Boca D., 1990, "The Effect of Taxation on Labour Supply in Italy", Journal of Human Resources, 25, 390-414 
[13] Colombino U. and Di Tommaso M., 1996, "A Simultaneous Model of Participation and Fertility in Italy", Labour, 10, 475-493

[14] Connelly R., 1992, "The Effect of Child Care Costs on Married Women's Labor Force Participation", Review of Economics and Statistics, 74, 8390

[15] Del Boca D., Locatelli M.and Pasqua S., 2000, "Employment Decisionsof Married Women: Evidence and Explanations", Labour, 14, 35-52

[16] Del Boca D., Locatelli M. and Vuri D., 2003, "Child Care Choices by Italian Households", CHILD WP 30/2003

[17] Del Boca D., 2002, "The Effect of Child Care and Part-Time on Participation and Fertility of Italian Women", Journal of Population Economics, 15, 549-573

[18] Di Tommaso M. L., 1999, "A Trivariate Model of Participation, Fertility and Wages: The Italian Case", Cambridge Journal of Economics, 23, 623-640

[19] Ermisch J. F., 1989, "Purchased Child Care, Optimal Family Size and Mother's Employment: Theory and Econometric Analysis", Journal of Population Economics, 2, 79-10

[20] Esping-Andersen G., 1999, Social Foundations of Post Industrial Economies, Oxford, Oxford University Press

[21] Engelhardt H., Kögel T. and Prskawetz A., 2003, "Fertility and Female Employment Reconsidered: a Macro-Level Time Series Analysis for Developed Countries", Max Planck Institute for Demographic Research, Rostock, Germany

[22] Francesconi M., 2002, "A Joint Dynamic Model of Fertility and Work of Married Women", Journal of Labor Economics, 20, 336-380

[23] Gauthier A.H. and Hatzius J., 1997, "Family Benefits and Fertility: An Econometric Analysis", Population Studies, 51, 295-306

[24] Gornick J.C., Meyers M.K. and Ross K. E., 1997, "Supporting the Employment of Mothers: Policy Variation across Fourteen Welfare states", Journal of European Social Policy, 7, 45 
[25] Gustafsson, Siv, Cecile Wetzels, Jan Dirk Vlasblom and Shirley Dex (1996), Labour Force Transitions in Connection With Child Birth A Panel Data Comparison Between Germany, Great Britain and Sweden, Journal of Population Economics 9,45-60

[26] Hotz V.J. and Miller R.A.,1988, "An Empirical Analysis of Life Cycle Fertility and Female Labor Supply", Econometrica, 56, 91-11

[27] Ichino A. and Sanz de Gadeano A., 2003, "Reconciling Motherhood and Work", mimeo EUI

[28] Kamerman S. and Kahn A., 2000, Child Care parental Leave and the under 3s, Auburn House

[29] Kimmel J., 1998, "Child Care Costs as a Barrier to Employment for Single and Married Mothers", The Review of Economics and Statistics, $80,287-299$

[30] Kogel H., 2004, "Did the Association Between Fertility and Female Employment Within OECD Countries Really Change its Sign?", Journal of Population Economics, 17, 45-65

[31] Kolher H. P., Billari F.C. and Ortega J. A, 2002, "The Emergence of Lowest Low Fertility in Europe During the 1990s", Population and Development Review 28, 641-680

[32] Laroque G. and Selanie B., 2003, "Fertility and Financial Incentives", mimeo

[33] Locatelli M., Moscato V. and Pasqua S., 2001, "The European Community Household Panel (ECHP): elements for users whith special focus on labour and household economics", CHILD WP 24/2001

[34] Moffitt R., 1984, "Profiles of Fertility, Labour Supply and Wages of Married Women: A Complete Life-Cycle Model", Review of Economic Studies, 51, 263-78

[35] Marenzi A. Pagani L., 2003, "The Labor Market Participation of Sandwich Generation Italian Women", mimeo 2003

[36] Mincer J., 1985, "Intercountry Comparisons of Labor Force Trends and of Related Developments: An Overview", Journal of Labor Economics, 3, S1-S32 
[37] Pissarides C., Garibaldi P., Olivetti C., Petrongolo B. and Weser E., 2003, "Women in the Labour Force: How Well is Europe Doing?", in Del Boca D., Pissarides C. and Boeri T. (eds), European Women at Work, Oxford University Press

[38] Ribar D., 1992, "Child Care and the Labour Supply of Married Women: Reduced Form Evidence", Journal of Human Resources, 27, 135-165

[39] Rosenzweig M. and Wolpin K.I., 1980, "Life-Cycle Labor Supply and Fertility: Casual Inferences From Household Models", Journal of Political Economy, 88, 328-348

[40] Wetzels, Cecile (2001), Squeezing Birth into Working Life, household panel data analysis comparing Britain, Germany, the Netherlands and Sweden. Ashgate Publishing Ltd. Aldershot, Hampshire

[41] Willis R.J., 1973, "A New approach to the Economic Theory of Fertility Behavior", Journal of Political Economy, 81, 3-18 